\title{
A non-internalised CD38-binding radiolabelled single-domain antibody fragment to monitor and treat multiple myeloma
}

\author{
Elodie Duray ${ }^{1,4}$, Margaux Lejeune ${ }^{1}$, Frederic Baron ${ }^{1,5}$, Yves Beguin ${ }^{1,5}$, Nick Devoogdt ${ }^{2}$, Ahmet Krasniqi², \\ Yoline Lauwers ${ }^{2}$, Yong Juan Zhao ${ }^{3}$, Matthias D'Huyvetter ${ }^{2+}$, Mireille Dumoulin ${ }^{4 \dagger}$ and Jo Caers ${ }^{1,5^{*}+}$ (i)
}

\begin{abstract}
Background: Antibody-based therapies targeting CD38 are currently used as single agents as well as in combination regimens for multiple myeloma, a malignant plasma cell disorder. In this study, we aimed to develop anti-CD38 single-domain antibodies (sdAbs) that can be used to trace $\mathrm{CD}_{3} 8^{+}$tumour cells and subsequently used for targeted radionuclide therapy. SdAbs are derived from Camelidae heavy-chain antibodies and have emerged as promising theranostic agents due to their favourable pharmacological properties.
\end{abstract}

Methods: Four different anti-CD38 sdAbs were produced, and their binding affinities and potential competition with the monoclonal antibody daratumumab were tested using biolayer interferometry. Their binding kinetics and potential cell internalisation were further studied after radiolabelling with the diagnostic radioisotope Indium-111. The resulting radiotracers were evaluated in vivo for their tumour-targeting potential and biodistribution through singlephoton emission computed tomography (SPECT/CT) imaging and serial dissections. Finally, therapeutic efficacy of a lead anti-CD38 sdAb, radiolabelled with the therapeutic radioisotope Lutetium-177, was evaluated in a CD38 ${ }^{+}$MM xenograft model.

Results: We retained anti-CD38 sdAb \#2F8 as lead based on its excellent affinity and superior stability, the absence of competition with daratumumab and the lack of receptor-mediated internalisation. When intravenously administered to tumour-xenografted mice, radiolabelled sdAb \#2F8 revealed specific and sustained tumour retention with low accumulation in other tissues, except kidneys, resulting in high tumour-to-normal tissue ratios. In a therapeutic setting, myeloma-bearing mice received three consecutive intravenous administrations of a high (18.5 MBq) or a low radioactive dose $(9.3 \mathrm{MBq})$ of ${ }^{177} \mathrm{Lu}-\mathrm{DTPA}-2 \mathrm{~F} 8$ or an equal volume of vehicle solution. A dose-dependent tumour regression was observed, which translated into a prolonged median survival from 43 days for vehicle-treated mice, to 62 days $(p=0.027)$ in mice receiving the low and 65 days in mice receiving the high ( $p=0.0007)$ radioactive dose regimen, respectively.

Conclusions: These results highlight the theranostic potential of radiolabelled anti-CD38 sdAbs for the monitoring and treatment of multiple myeloma.

\footnotetext{
*Correspondence: jo.caers@chuliege.be

${ }^{\dagger}$ Matthias D'Huyvetter, Mireille Dumoulin and Jo Caers are co-senior

authors

${ }^{1}$ Laboratory of Haematology, GIGA-13, University of Liège, Liège, Belgium

Full list of author information is available at the end of the article
} permits use, sharing, adaptation, distribution and reproduction in any medium or format, as long as you give appropriate credit to the original author(s) and the source, provide a link to the Creative Commons licence, and indicate if changes were made. The images or other third party material in this article are included in the article's Creative Commons licence, unless indicated otherwise in a credit line to the material. If material is not included in the article's Creative Commons licence and your intended use is not permitted by statutory regulation or exceeds the permitted use, you will need to obtain permission directly from the copyright holder. To view a copy of this licence, visit http://creativecommons.org/licenses/by/4.0/. The Creative Commons Public Domain Dedication waiver (http://creativeco mmons.org/publicdomain/zero/1.0/) applies to the data made available in this article, unless otherwise stated in a credit line to the data. 
Keywords: Multiple myeloma, CD38, Theranostic, Single-domain antibody, Nanobody, Radio-immunotherapy,

Targeted radionuclide therapy

\section{Introduction}

The field of theranostics represents the clinic's ongoing efforts to develop more specific and individualised therapies for various diseases and to combine diagnostic and therapeutic capabilities into a single pharmaceutical agent [1]. Nuclear medicine is ideally positioned to play a central role in theranostics. Indeed, diagnostic radionuclides linked to an antigen-binding vector allow to visualise molecular targets, to provide non-invasive information on biomarker expression, to select patients for targeted therapies and to monitor therapy responses. Conjugating that same vector to therapeutic radionuclides enables targeted radionuclide therapy (TRNT).

Immunotherapy is revolutionising the treatment of multiple myeloma (MM). This disease, characterised by the clonal proliferation of malignant plasma cells in the bone marrow, has a high unmet therapeutic need [2]. Daratumumab is the first-in-class CD38-binding monoclonal antibody $(\mathrm{mAb})$ that is currently FDA- and EMAapproved for monotherapy or combination therapy for relapsed MM, based on impressive results in large phase 3 trials [3]. Unfortunately, not all pre-treated patients respond to daratumumab, and some patients who initially respond eventually become resistant to the treatment. Although baseline CD38 levels are predictive of response, they are not routinely evaluated before the initiation of daratumumab treatment. Therefore, there is a need for theranostic agents to identify and treat patients who might benefit from anti-CD38-based therapies.

Different CD38-targeting agents have been integrated in theranostic constructs including mAbs, single-chain variable fragments $(\mathrm{scFv})$ and single-domain antibodies (sdAbs) [4-7]. They were either directly or indirectly coupled to diagnostic or therapeutic radionuclides, or fluorochromes. Single-domain antibody fragments (sdAbs) are derived from Camelidae heavy-chain antibodies and have emerged as promising vectors [8]. Due to their small size, sdAbs have favourable pharmacological properties compared to conventional Abs or Ab fragments, including an improved tissue penetration, a fast clearance from the circulation and a high conformational stability (Additional file 1: Fig. 1). Moreover, their straightforward production and engineering allow researchers to adapt and include them into a variety of applications [9-11]. Finally, their long flexible antigen-binding loops allow the
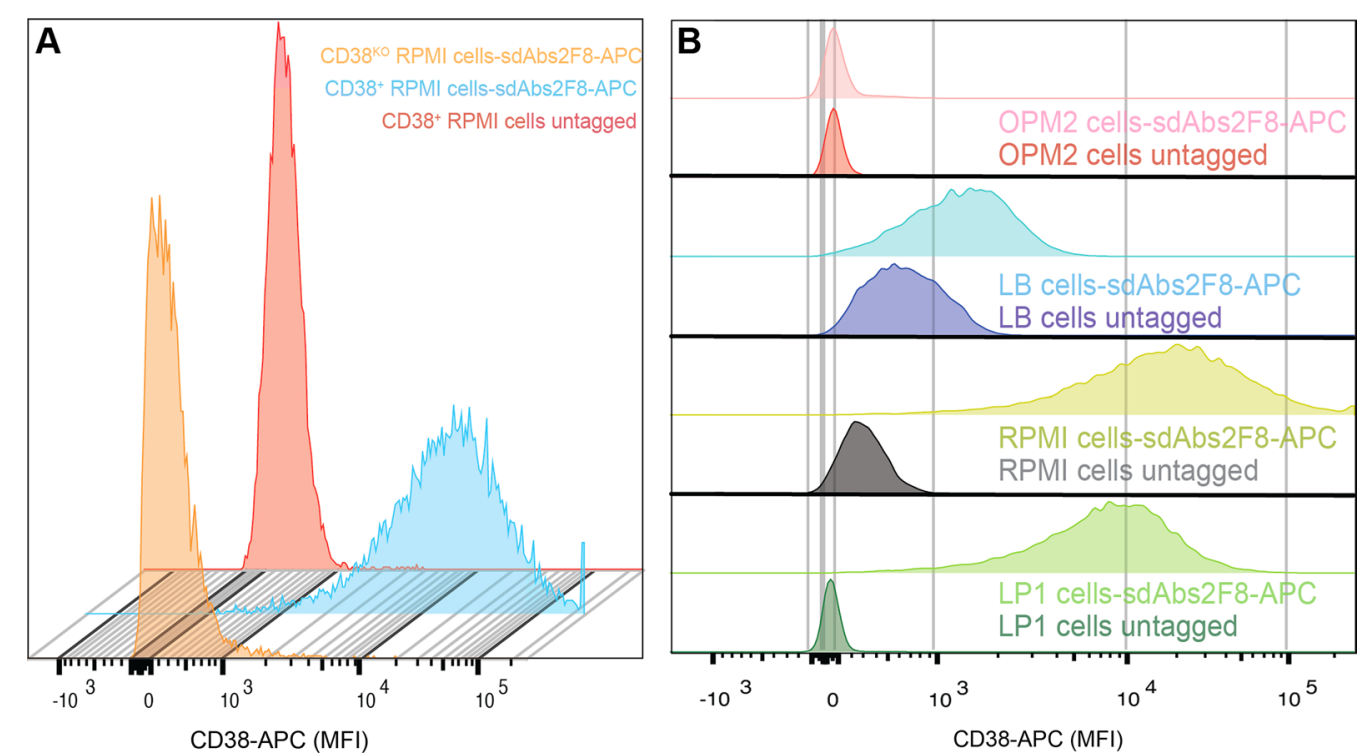

Fig. 1 Monoparametric representations of labelled tumour cells with APC from flow cytometry experiments. Image obtained from density plot (FSC/SSC) with single marker APC. a Histogram of the mean fluorescence intensity measured on RPMl cells' surface. The red peak corresponds to RPMI 8226 stained with the secondary APC-labelled anti- $\mathrm{H}_{6}$ mAb alone. The blue one shows the staining of RPMI 8226 with sdAb \#2F8 followed by the secondary $\mathrm{Ab}$ and the orange peak a similar staining on $\mathrm{CD} 38^{\mathrm{KO}}$ cells. $\mathbf{b}$ Histograms of the 2F8's association to the surface of different cell lines expressing (LP1, RPMI, LB5871-LYMP (LB) or not (OPM2) the CD38 receptor. A clear binding of the sdAb \#2F8 to the surface of LP1 (light green) and RPMI cells (yellow) is observed. SdAb \#2F8 also binds to the surface of lymphoma cells, although less significantly (LB, light blue). No interactions were identified on the OPM2's membrane (red peaks) 
recognition of buried epitopes, and they appear not to be immunogenic [12].

In this work, we describe the development of a radiolabelled $\mathrm{sdAb}$ as a theranostic agent targeting CD38 that could ultimately predict responsiveness to and at the same time allow for an anti-CD38 treatment strategy.

\section{Material and methods}

\section{Expression and purification of His-tagged and untagged} sdAbs

Non-targeting control sdAbs cAb-BcII10 and R3B23 were generated as described before [13]. To obtain the four hexahistidine $\left(\mathrm{His}_{6}\right)$-tagged sdAbs (i.e. \#551 [5], \#375 [5], \#1053 [5] and \#2F8 [14]), their genes were cloned into the expression vectors pHEN2 or pHEN6 and subsequently transformed into the E. coli WK6 cells [15]. These Histagged sdAbs were purified by metal chelate affinity chromatography [10]. Residual imidazole was removed by gel filtration (Sephadex G25). A stop-codon was introduced by mutation before the His-tag coding region to produce untagged nanobodies \#551 and \#2F8. Untagged sdAbs were produced and subsequently purified by combining ionic exchange (high TRAP Q HP and Capto $S$ resin) and size exclusion chromatography (Superdex 75) in $50 \mathrm{mM}$ HEPES, $150 \mathrm{mM} \mathrm{NaCl}$. The purity and integrity of sdAbs were evaluated by SDS-PAGE and by mass spectrometry analysis.

\section{Characterisation of anti-CD38 sdAbs Flow cytometry}

The specific binding of sdAbs to cells expressing CD38 was assessed using different cancer cell lines, such as RPMI 8226 cells $\left(\mathrm{CD} 38^{+}\right.$or $\mathrm{CD} 38^{\mathrm{KO}}$ ), LP1, K562, U266 and LB5871-LYMP. Cells were incubated with $100 \mathrm{nM}$ of purified $\mathrm{His}_{6}$-tagged sdAbs for $30 \mathrm{~min}$ at $4{ }^{\circ} \mathrm{C}$. After washing with PBS-3\%FBS, the cells were incubated with a secondary antibody (APC-conjugated anti-His mAb, BioLegend). Stained cells were analysed on a BD FACSArray $^{\mathrm{TM}}$ Bioanalyzer System (BD Biosciences). An irrelevant non-targeting sdAb (cAb-BcII10) was used as a reference for non-specific binding. To study the internalisation of sdAb \#2F8, the same cells were incubated with $10 \mathrm{nM}$ sdAb $2 \mathrm{~F} 8$ at $37^{\circ} \mathrm{C}$ over time. At different time points during incubation, cells were labelled with the secondary anti-His $\mathrm{mAb}$ to measure the dynamics of sdAbs bound to the cell membrane.

\section{Biolayer interferometry}

To assess the binding affinity by interferometry using the OctetHTX platform, streptavidin (SA)-coated biosensor tips (Pall ForteBio) were used to capture the biotinylated extracellular domain of the CD38. Kinetic measurements for sdAb binding were performed by dipping the CD38coated biosensors into wells containing seven different concentrations of the corresponding sdAbs (from 2.5 to $50 \mathrm{nM}$ ), followed by a dissociation time by transferring the biosensors into buffer-containing wells. All sensorgrams were referenced for buffer effects and then fitted using the OctetHTX user software. Kinetic responses were fitted to a 1:1 binding model to obtain values for association $\left(\mathrm{k}_{\mathrm{on}}\right)$ and dissociation $\left(\mathrm{k}_{\mathrm{off}}\right)$ rate constants, and the equilibrium dissociation constant $\left(\mathrm{K}_{\mathrm{D}}\right)$. This experiment was also performed for DTPA-conjugated \#2F8 but with four different concentrations (from 20 to $100 \mathrm{nM}$ ). Competition between antibodies for CD38 binding was assessed by dipping the CD38-coated biosensors into wells containing a first antibody of interest $(100 \mathrm{nM})$ until saturation (first association). Then, the sensors were immersed into a well containing the first and second antibodies (100 nM) (second association) allowing to monitor the binding capacities of the second antibody in the presence of the first one.

\section{Protein stability}

Circular dichroism (CD) measurements were taken with a 810 Jasco Spectrophotometer, either in the far UV $(190-250 \mathrm{~nm})$ or in the near UV $(250-350 \mathrm{~nm})$ regions, using a sdAb concentration of $0.2 \mathrm{mg} / \mathrm{mL}$ in $50 \mathrm{mM}$ sodium buffer, and $0.1-\mathrm{cm}$ or $1-\mathrm{cm}$ pathlength quartz cell, respectively. Spectra were acquired at a scan speed of $50 \mathrm{~nm} / \mathrm{min}$, with a 1-nm bandwidth, a 2-s integration time and at $25{ }^{\circ} \mathrm{C}$. Five spectrums were acquired, averaged and corrected by subtracting the buffer spectrum recorded under identical conditions. Thermal unfolding experiments were monitored at $205 \mathrm{~nm}$ by raising the temperature from 25 to $97^{\circ} \mathrm{C}$ at a rate of $0.5^{\circ} \mathrm{C} / \mathrm{min}$. The reversibility of the transition was assayed by cooling the sample down to $25^{\circ} \mathrm{C}$. Data were acquired with a 4-s integration time and a 1-nm bandwidth. The heatinduced unfolding transitions monitored were used to determine the mid-transition temperature $\left(\mathrm{T}_{\mathrm{m}}\right.$, temperature at which $50 \%$ of the protein molecules are unfolded, while the remaining are native) by fitting the experimental data with the equation of a two-state model [16]. Since the transitions were not reversible, only apparent $\mathrm{Tm}$ could be determined $\left(\mathrm{Tm}^{*}\right)$.

\section{Cell line and mouse model}

The human MM cancer cell line RPMI $8226\left(\mathrm{GFP}^{+} /\right.$Luciferase $^{+}$) was obtained from A. Martens (Haematology department, VU University Medical Center, The Netherlands). RPMI 8226 cells were cultured using Roswell Park Memorial Institute medium (RPMI 1640, Lonza, Belgium) enriched with $10 \%$ foetal bovine serum, $100 \mathrm{U} / \mathrm{mL}$ 
penicillin and $0.1 \mathrm{mg} / \mathrm{mL}$ streptomycin. $\mathrm{K} 562$ cells were purchased from ATCC (Manassas, Virginia, US), doublehit lymphoma cell line LB5871-LYMP was obtained from N. Van Baren (UCL, Brussels) [17], and finally, U266, OPM2 and LP-1 cell lines were obtained from H. Jernberg-Wiklund (Uppsala University, Sweden), respectively.

The CD38 knockout (KO) cells used as specific controls were obtained by genetic engineering using the CRISPR/ Cas9 technique as previously described [18].

Tumour xenografts were obtained by subcutaneously (s.c.) inoculating 6- to 12-week-old NOD.Cg-Prkdc ${ }^{\text {sci }}$

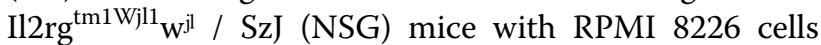
$\left(0.5 \times 10^{6}\right)$ in $150 \mu \mathrm{L}$ PBS-Matrigel (ratio 1:1) into the left hind. Mice were irradiated with 2 Gy 24 h before cell injection to favour a homogenous tumour uptake. Tumour development was followed from day 14 (palpable from day 19) using an IVIS Spectrum In Vivo Imaging System (PerkinElmer). Briefly, after s.c. injection of D-luciferin $(150 \mathrm{mg} / \mathrm{kg})$, anaesthetised mice were imaged (scan and reading of luminescence emitted during substrate degradation by cancer cells expressing the luciferase). All animal experiments were approved by the Ethical Committee for Animal Experiments of the University of Liège and of Vrije Universiteit Brussel.

\section{Nuclear imaging using ${ }^{99 \mathrm{~m}} \mathrm{Tc}$-sdAbs}

Anti-CD38 sdAbs were radiolabelled with ${ }^{99} \mathrm{~m}$ Tc at their $\mathrm{C}$-terminal $\mathrm{His}_{6}$-tag using the Isolink labelling kit (Mallinckrodt Medical BV), as previously described [19]. ${ }^{99 \mathrm{~m}} \mathrm{Tc}$-sdAbs were separated from unreacted $\left[{ }^{99 \mathrm{~m}} \mathrm{Tc}\left(\mathrm{H}_{2} \mathrm{O}\right)_{3}(\mathrm{CO})_{3}\right]^{+}$via NAP-5 size exclusion chromatography (Sephadex, GE Healthcare). The eluate was passed through a $0.22 \mu \mathrm{m}$ filter (Millipore), and radiochemical purity (RCP) was determined by instant thinlayer chromatography (iTLC) using acetone as running buffer (iTLC-SG, Pall Corporation) and was $>95 \%$. Mice bearing s.c. $\mathrm{CD}^{+} 8^{+}$RPMI 8226 tumours $(\mathrm{n}=3)$ were intravenously (i.v.) injected with ${ }^{99 \mathrm{~m}} \mathrm{Tc}$-labelled sdAbs (about $4 \mu \mathrm{g}$ and $51.1 \pm 3.7 \mathrm{MBq}$ ). At $1 \mathrm{~h}$ post-injection (p.i.), mice were imaged using pinhole single-photon emission computed tomography (SPECT)/ computed tomography (CT) with a Vector +/CT MILabs system [20]. Images were obtained using a rat SPECT-collimator (1.5- $\mathrm{mm}$ pinholes) in spiral mode, 7 positions with $128 \mathrm{~s}$ per position for whole-body imaging. Images were reconstructed with $0.4 \mathrm{~mm}^{3}$ voxels with 2 subsets and 2 iterations, without post-reconstruction filter. For CT, a normal scan mode of two positions was used. Images were fused and corrected for attenuation based on the CT scan. Image analysis was performed using a
Medical Image Data Examiner (AMIDE) software and data expressed as \% injected activity per $\mathrm{cm}^{3}\left(\% \mathrm{IA} / \mathrm{cm}^{3}\right)$ [21]. After imaging, mice were killed, and organs and tissues were isolated and weighed. The radioactivity in each sample was measured using a Wizard $2 \gamma$-counter (PerkinElmer). Tracer uptake was expressed as \% injected activity per gram organ $(\% \mathrm{IA} / \mathrm{g})$.

\section{Preparation of ${ }^{111}$ In- and ${ }^{177}$ Lu-DTPA-sdAbs}

Untagged \#2F8 and R3B23 $(3 \mathrm{mg} / \mathrm{mL})$ reconstituted in $50 \mathrm{mM}$ sodium carbonate buffer $\mathrm{pH} 8.5$ were reacted with a tenfold molar excess of bifunctional chelator CHX-A"-DTPA (Macrocyclics) for $3 \mathrm{~h}$ at RT, as described previously [22]. The conjugation reaction was quenched by reducing the $\mathrm{pH}$ of the mixture to $\mathrm{pH}$ 7.0. DTPA-2F8 was purified on Superdex 75 10/300 GL (GE Healthcare) in $0.1 \mathrm{M}$ ammonium acetate buffer $\mathrm{pH}$ 7.0. The necessary amount of ${ }^{111} \mathrm{In}\left(54\right.$ to $270 \mathrm{MBq}$ ) or ${ }^{177} \mathrm{Lu}(74 \mathrm{MBq}$ to $1 \mathrm{GBq}$ ) was incubated for $30 \mathrm{~min}$ at $\mathrm{RT}$ or $37^{\circ} \mathrm{C}$, respectively, with the DTPA-2F8 in $200 \mathrm{mM}$ ammonium acetate pH 5. Resulting ${ }^{111}$ In- and ${ }^{177} \mathrm{Lu}$-DTPA-2F8 were purified on NAP-5 column (GE Healthcare) using $0.9 \% \mathrm{NaCl}$ as eluent. In case of high radioactive labelling for preclinical therapy, $0.9 \% \mathrm{NaCl}$ with $5 \mathrm{mg} / \mathrm{mL}$ ascorbic acid was used. The resulting radio-conjugates were filtered on $0.22 \mu \mathrm{m}$ after which RCP was determined by iTLC with citric acid as running buffer (iTLC-SG, Pall Corporation) and measured $>96 \%$.

\section{In vitro evaluation of ${ }^{111}$ In-DTPA-2F8}

Binding affinity and degree of internalisation of ${ }^{111}$ In-DTPA-2F8 were evaluated as previously described [23]. In case of assessing binding affinity, $\mathrm{CD} 38^{+} \mathrm{RPMI}$ 8226 cells were incubated for $1 \mathrm{~h}$ at $4{ }^{\circ} \mathrm{C}$ with a serial dilution of ${ }^{111}$ In-DTPA-2F8 $(0.1-300 \mathrm{nM})$ alone or in combination with a 100 -fold molar excess of unlabelled 2F8 to assess non-specific binding. Next, unbound $\mathrm{sdAb}$ was washed away, after which retained radioactivity was measured in a $\gamma$-counter. Data were plotted using GraphPad Prism software. To study the level of receptor-mediated internalisation, RPMI 8226 cells were incubated for $1 \mathrm{~h}$ at $4{ }^{\circ} \mathrm{C}$ with $10 \mathrm{nM}$ of ${ }^{111}$ In-DTPA-2F8, alone or in combination with a 100 fold molar excess of unlabelled \#2F8 to assess unspecific binding. After washing, the cells were incubated at $37{ }^{\circ} \mathrm{C}$ up to $24 \mathrm{~h}$. At different time points during incubation, cells were processed to obtain the corresponding dissociated, membrane-bound and internalised fraction, as described before [23]. All fractions were measured for radioactivity in a $\gamma$-counter. 
Nuclear imaging using ${ }^{111}$ In-DTPA-sdAbs

Mice bearing s.c. CD38 ${ }^{+}$RPMI 8226 tumours $(n=3)$ were i.v. injected with ${ }^{111}$ In-DTPA-2F8 (about $18.8 \pm 0.1 \mathrm{MBq}$ ) or $\mathrm{R} 3 \mathrm{~B} 23$ and $150 \mathrm{mg} / \mathrm{kg}$ gelofusin. SPECT images were taken at different time points up to $48 \mathrm{~h}$ p.i. Images were obtained using the same scan parameters used as described for ${ }^{99 \mathrm{~m}} \mathrm{Tc}$ acquisitions, except for the number of positions [6] and time per position for the full body imaging (150 s) and number of iterations (6 instead of 7). After the last image acquisition, mice were killed and processed as described above. In parallel, a few animals $(n=3)$ were i.v. injected $(4.5 \pm 0.2 \mathrm{MBq})$ with ${ }^{111}$ In-DTPA-2F8 or ${ }^{111}$ In-DTPA-R3B23, alone or as a co-injection with $150 \mathrm{mg} / \mathrm{kg}$ gelofusin. They were imaged $1 \mathrm{~h}$ post-injection in order to evaluate the effect of gelofusin on the renal retention of the tracer.

\section{Biodistribution and dosimetry ${ }^{177}$ Lu-DTPA-2F8}

Mice bearing $\mathrm{CD}^{+} 8^{+} \mathrm{RPMI} 8226$ tumours were i.v. injected with ${ }^{177}$ Lu-DTPA-2F8 (about $4 \mu \mathrm{g}$ and $4.5 \pm 0.2 \mathrm{MBq}$ ) co-infused with $150 \mathrm{mg} / \mathrm{kg}$ gelofusin $(n=3)$. Next, mice were killed at different time points up to $48 \mathrm{~h}$ p.i., followed by the isolation of different organs and tissues. All samples were weighed and counted for radioactivity content against a standard of known radioactivity using a $\gamma$-counter and expressed as percentage of the injected activity per gram of tissue mass (\% IA/g), corrected for decay. For dosimetry purposes, the biodistribution data were time-integrated to obtain the residence time per gram tissue [22]. Briefly, the area under the curve between 1 and $48 \mathrm{~h}$ was made using the trapezoid integration method. Next, the absorbed doses were calculated using $S$ values for ${ }^{177} \mathrm{Lu}$ obtained from RADAR phantoms (Unit Density Spheres).

\section{Targeted radionuclide therapy using ${ }^{177}$ Lu-DTPA-2F8}

Day 23 post-cell inoculation, mice with palpable $\mathrm{CD}^{+} 8^{+}$ RPMI 8226 tumours were randomly categorised into three treatment groups $(n=10)$. Mice received three consecutive i.v. administrations, once every two days, of either: (i) a high radioactive dose (about $18.5 \pm 0.5 \mathrm{MBq}$ ), (ii) a low radioactive dose $(9.3 \pm 0.3 \mathrm{MBq}){ }^{177} \mathrm{Lu}-\mathrm{DTPA}-$ $2 \mathrm{~F} 8+150 \mathrm{mg} / \mathrm{kg}$ gelofusin, or (iii) an equal volume of vehicle solution (PBS). Animals were followed up over time through body condition scoring (weight, physical appearance, mobility and behaviour), and tumour volume was assessed via calliper measurements and bioluminescence imaging as described above.

\section{Results}

\section{In vitro characterisation of sdAbs}

Flow cytometry experiments revealed the specific binding of the different anti-CD38 sdAbs. Indeed, all of them are capable of binding the CD38 antigen on MM cell lines (RPMI 8226 and LP1) and non-Hodgkin's lymphoma cells (LB5871-LYMP), while no specific binding was observed on the CD38 ${ }^{-}$cells (K562 cell line) and $\mathrm{CD} 38^{\mathrm{KO}}$ cell lines (Fig. 1). Non-targeting cAb-BcII10 did not show specific binding to CD38. 2F8 binds CD38 with an affinity in the low $\left(\mathrm{K}_{\mathrm{D}} 1.5 \mathrm{nM}\right)$ nanomolar range as illustrated in Fig. 2. Apparent midpoint of the heat-induced unfolding $\left(\mathrm{Tm}^{*}\right)$, ranged from 69 to $89{ }^{\circ} \mathrm{C}$, were obtained for the studied sdAbs with the \#2F8 protein showing the highest one $\left(88.7 \pm 0.3{ }^{\circ} \mathrm{C}\right)$. To determine potential competition for CD38 targeting between daratumumab and the different sdAbs, competitive biolayer interferometry (BLI) experiments were performed. Different levels of competition with daratumumab were defined: total, partial or null. No binding of sdAbs \#1053 or \#375 was detected on CD38 that was pre-incubated with daratumumab, and vice versa. In contrast, sdAb \#2F8 still bound in full capacity, and sdAb \#551 in part, to the extracellular domain of CD38 in the presence of daratumumab (Fig. 2). The set of data acquired for the other three sdAbs are summarised in Table 1.

\section{Biodistribution of ${ }^{99 m} \mathrm{Tc}$-labelled sdAbs}

The biodistribution and tumour-targeting potential of different ${ }^{99 \mathrm{~m}}$ Tc-labelled sdAbs were assessed via pinhole $\mu$ SPECT/CT imaging and dissection. The resulting uptake values in tumours and non-target organs are summarised in Table 1. Administration of ${ }^{99 \mathrm{~m}} \mathrm{Tc}_{\mathrm{C}} \mathrm{H}_{6}-2 \mathrm{~F} 8$ revealed a tumour uptake of $2.22 \pm 0.47 \% \mathrm{IA} / \mathrm{g}$ compared to only $0.79 \pm 0.11 \% \mathrm{IA} / \mathrm{g}$ for ${ }^{99 \mathrm{~m}} \mathrm{Tc}-\mathrm{H}_{6}$-cAb-BCII10, with good contrasts observed early after tracer administration (Fig. 3). In addition, ${ }^{99} \mathrm{~m}_{\mathrm{Tc}}-\mathrm{H}_{6}-2 \mathrm{~F} 8$ was found concentrated in kidneys and bladder, in line with the fast blood clearance of sdAbs [24]. Only low amounts of radioactivity were measured in blood $(0.39 \pm 0.09 \% \mathrm{IA} / \mathrm{g})$ and non-targeted organs and tissues (from $0.02 \pm 0.01$ to $0.53 \pm 0.12 \% \mathrm{IA} / \mathrm{g}$ ) (Additional file 1: Table 1).

\section{Saturation binding and degree of internalisation of ${ }^{111}$ In-labelled sdAb 2 F8}

Based on the superior in vitro and in vivo characteristics, sdAb \#2F8 was selected as lead CD38-targeting compound (Table 1). Untagged \#2F8 was conjugated to p-SCN-Bn-CHX-A"-DTPA and was shown to maintain its binding characteristics as determined 


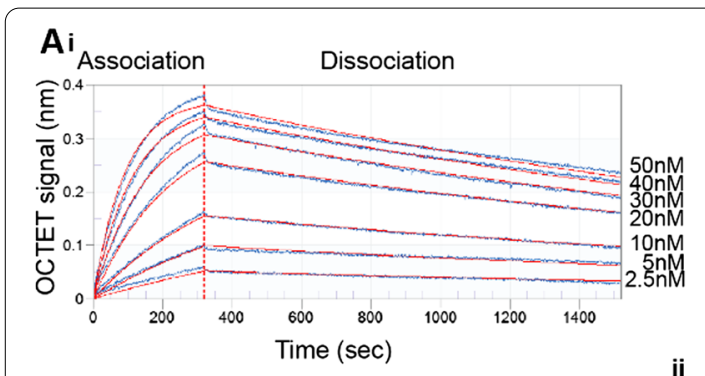

ii \begin{tabular}{c|c|c|c|}
\hline sdAb & $k_{\text {on }}\left(\mathrm{M}^{-1} \mathrm{~s}^{-1}\right)$ & $k_{\text {diss }}\left(\mathrm{s}^{-1}\right)$ & $K_{\mathrm{D}}(\mathrm{M})$ \\
\hline $2 \mathrm{FB}$ & $2.4310^{5} \pm 2.7110^{4}$ & $3.5510^{-4} \pm 3.0510^{-5}$ & $1.4810^{-9} \pm 2.1510^{-10}$ \\
\hline 551 & $5.3910^{4} \pm 7.8510^{3}$ & $7.8910^{-5} \pm 1.7610^{-5}$ & $1.5010^{-9} \pm 4.5810^{-10}$ \\
\hline 375 & $1.8610^{5} \pm 2.3110^{3}$ & $2.7610^{-4} \pm 3.3910^{-5}$ & $1.4910^{-9} \pm 1.9010^{-10}$ \\
\hline 1053 & $3.6210^{5} \pm 1.8010^{5}$ & $5.2010^{-4} \pm 8.4110^{-5}$ & $1.7010^{-9} \pm 7.0310^{-10}$ \\
\hline 2F8-DTPA & $2.5810^{5} \pm 3.2810^{2}$ & $4.1210^{-4} \pm 3.6210^{-7}$ & $1.6010^{-9} \pm 2.4710^{-11}$ \\
\hline
\end{tabular}

$\mathbf{B}_{\mathbf{i}}$
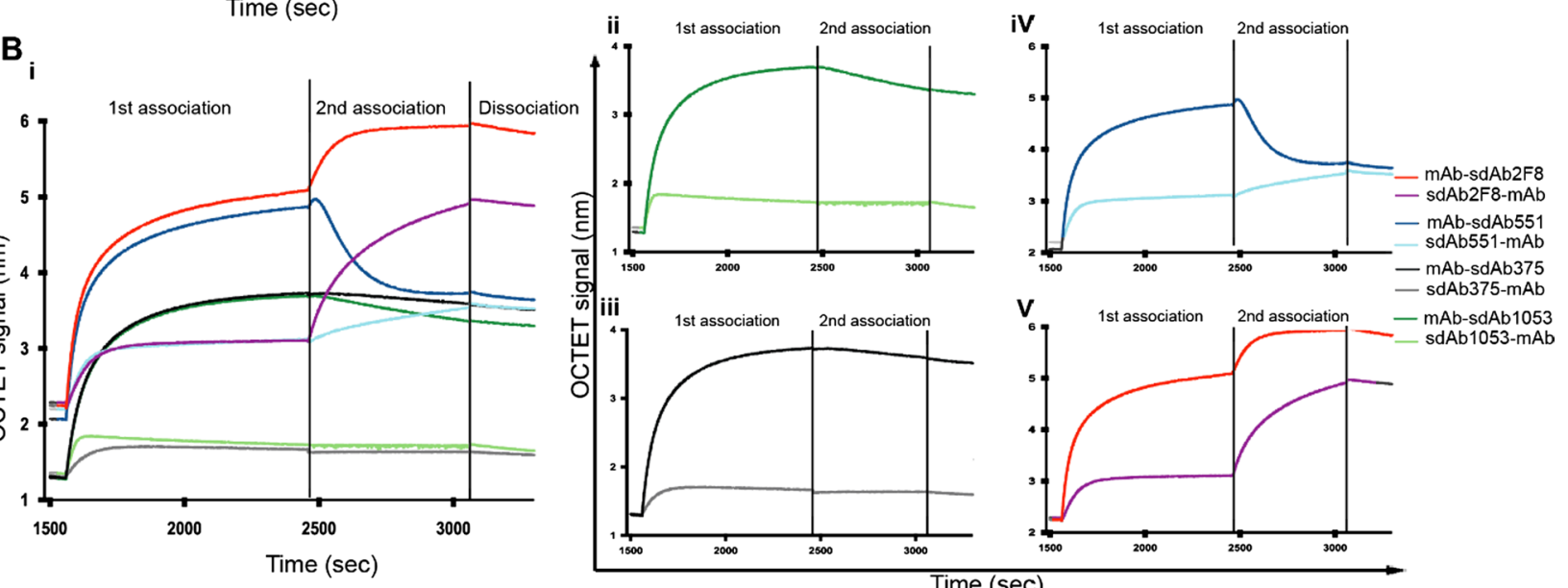

Fig. 2 a (i) Biolayer interferometry sensorgrams from a dilution series of sdAb \#2F8 from 50 to $2.5 \mathrm{nM}$ to assess its binding to the CD38. The blue curves represent the experimental kinetics, and the red ones represent fit curves. (ii) Summary of the different binding parameters for the sdAbs studied and the sdAb 2 F8 conjugated to the chelator DTPA used in radiolabelling with ${ }^{111}$ In and ${ }^{177}$ Lu. The data are expressed as mean \pm SD $(n=4)$. b (i) Competitive binding between daratumumab and sdAbs (\#2F8, \#551, \#375 or \#1053) for binding to the CD38, (ii) data obtained for competitor sdAb \#1053 and daratumumab, where no additional signal is observed upon addition of sdAb on mAb-CD38 complex (dark green) and vice versa (light green), (iii) similar results obtained for the sdAb \#375 (addition of sdAb on mAb-CD38 complex in black and the reverse in grey), (iv) partial-competitor sdAb \#551 and daratumumab where an additional signal is observed upon the addition of mAb on sdAb-CD38 complex but with a lower amplitude than when it was immobilised first (light blue). A decrease in signal after addition of sdAb on mAb-CD38 complex is observed (dark blue), which may indicate loss of binding for daratumumab. Finally, (v) non-competitor sdAb \#2F8 and daratumumab, where no competition is observed. The two proteins are able to bind the receptor without impacting the signal amplitude, regardless of the order of addition

Table 1 Summary of in vitro and in vivo characterisation of the different anti-CD38 sdAbs. The affinities and competition behaviour towards the human monoclonal antibody daratumumab were obtained by the biolayer interferometry method

\begin{tabular}{lllll}
\hline Parameters sdAbs & \#375 & \#1053 & \#551 & \#2F8 \\
\hline Affinity $\left(\mathrm{K}_{\mathrm{D}}\right)$ & $1.49 \mathrm{~nm}$ & $1.7 \mathrm{nM}$ & $1.50 \mathrm{nM}$ & $1.48 \mathrm{nM}$ \\
$\begin{array}{l}\text { Competition Vs daratumumab } \\
\text { Biodistribution }\end{array}$ & Competitor & Competitor & Partial competitor & Non-competitor \\
$\quad$ Location & $\mathrm{ND}$ & & & \\
Tumour & $\mathrm{ND}$ & $1.78 \pm 0.37$ & $3.37 \pm 0.38$ & $2.22 \pm 0.47$ \\
Blood & $\mathrm{ND}$ & $258.00 \pm 19.08$ & $402.20 \pm 22.46$ & $169.32 \pm 4.56$ \\
Liver & $\mathrm{ND}$ & $0.61 \pm 0.26$ & $1.33 \pm 0.08$ & $0.53 \pm 0.12$ \\
Thermal stability $\left(\mathrm{Tm}^{*}\right)$ & $69.1 \pm 0.1^{\circ} \mathrm{C}$ & $1.28 \pm 0.28$ & $1.33 \pm 0.08$ & $0.53 \pm 0.12$ \\
\hline
\end{tabular}

All the sdAbs have an affinity in the nanomolar range. \#375 and \#1053 are in competition with daratumumab, while a partial and no competition are observed for \#551 and \#2F8, respectively. The data included in the biodistribution section correspond to the results obtained after radiolabelling of sdAbs with the ${ }^{99 \mathrm{~m} T \mathrm{TC}}$ radioisotope (Fig. 3); \#551 and \#2F8 show the best tumour uptake. The thermal stability (Tm*) of the sdAbs was evaluated by far UV circular dichroism. The most stable is \#2F8. Based on these characteristics, sdAb 2F8 was chosen for further work. (ND: not-determined, protein not studied in vivo because its in vitro behaviour is similar to that of $s d A b$ 1053) 


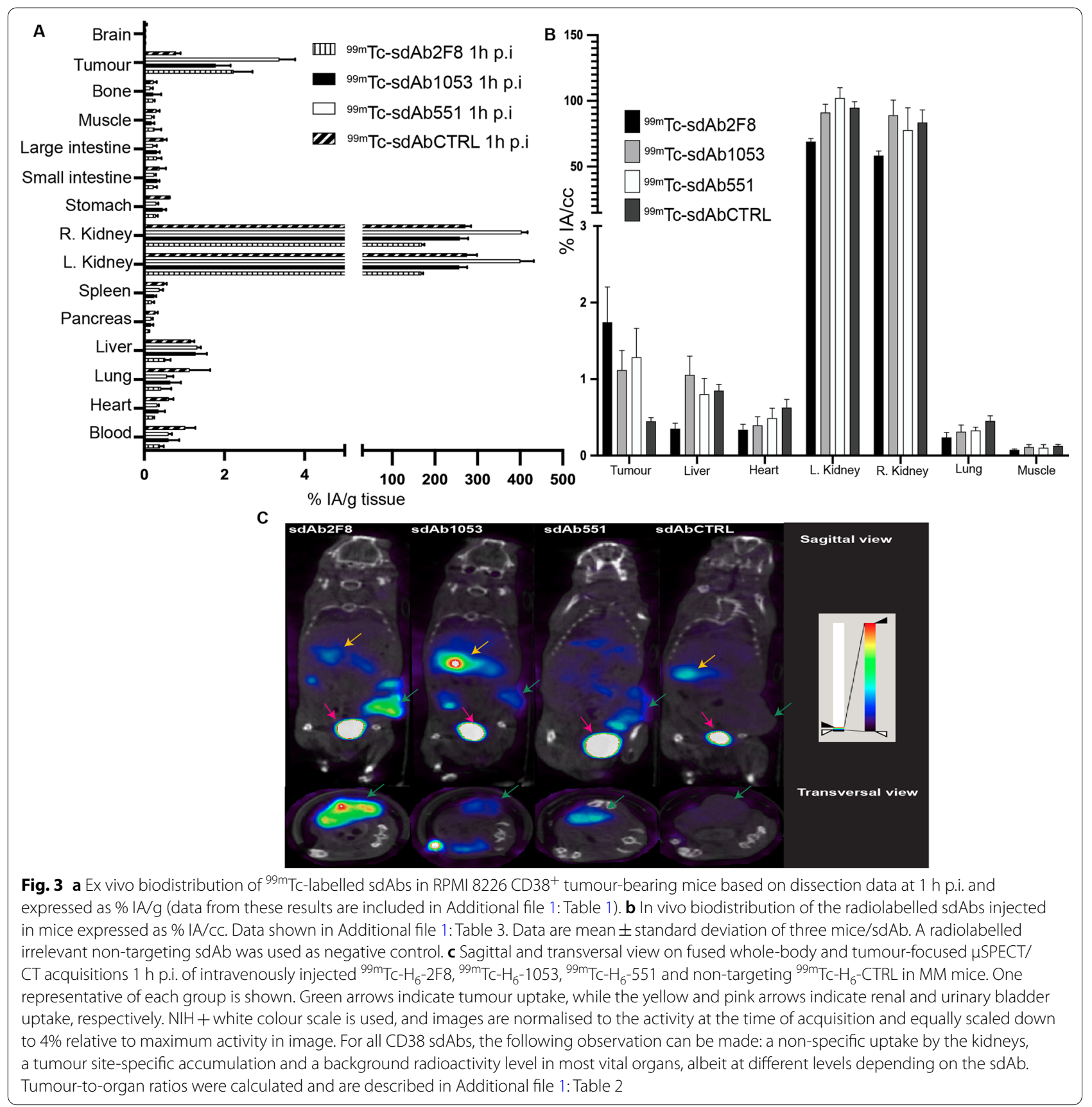

(See figure on next page.)

Fig. 4 a Saturation binding curve of ${ }^{111}$ In-DTPA-2F8 on RPMI 8226 cells. The maximal effective concentration (EC ${ }_{50}$ ) was calculated by subtracting non-specific-bound activity (assessed by adding an excess of unlabelled sdAb) from total bound activity and plotted in function of ${ }^{111}$ In-sdAb concentrations. Data are expressed as mean $\pm S D$. $\mathbf{b}$ Ex vivo biodistribution of ${ }^{111}$ In-DTPA- 2 F8 or R3B23 sdAbs. NOD scid gamma mice $(n=3)$ bearing RPMI 8226 tumour ( $10^{5}$ cells injected subcutaneously in the left side) were injected at $-1 \mathrm{~h}$ with $4.5 \pm 0.2 \mathrm{MBq}$ of radiolabelled sdAb and euthanised for organ harvesting. Data displayed on the bar graph are expressed as \% IA/g and detailed in Additional file 1: Table 4. c Cell-internalisation assays using sdAb \#2F8. (i) Plot representing the internalised fraction of ${ }^{111}$ In-radiolabelled sdAb \#2F8 over time, (ii) membrane-bound fraction of APC-anti-Histag-2F8 over time, assessed via flow cytometry. $\mathbf{d}$ In vivo biodistribution of ${ }^{111}$ In-labelled sdAb \#2F8 $(18.8 \pm 0.1 \mathrm{MBq})+150 \mathrm{mg} / \mathrm{kg}$ gelofusin for a selection of organs and tissues up to $48 \mathrm{~h}$ p.i. e Biodistribution of ${ }^{111}$ In-labelled sdAb \#2F8 and the non-targeting sdAb after 1 and $48 \mathrm{~h}$ post-tracer administration $(18.8 \pm 0.1 \mathrm{MBq})$. Both are co-injected with $150 \mathrm{mg} / \mathrm{kg}$ gelofusin. Data are presented as mean \pm SD $(n=3)$ and further detailed in Additional file 1: Tables 5 and 6 . Images illustrating these biodistributions are included in Additional file 1: Fig. 2 


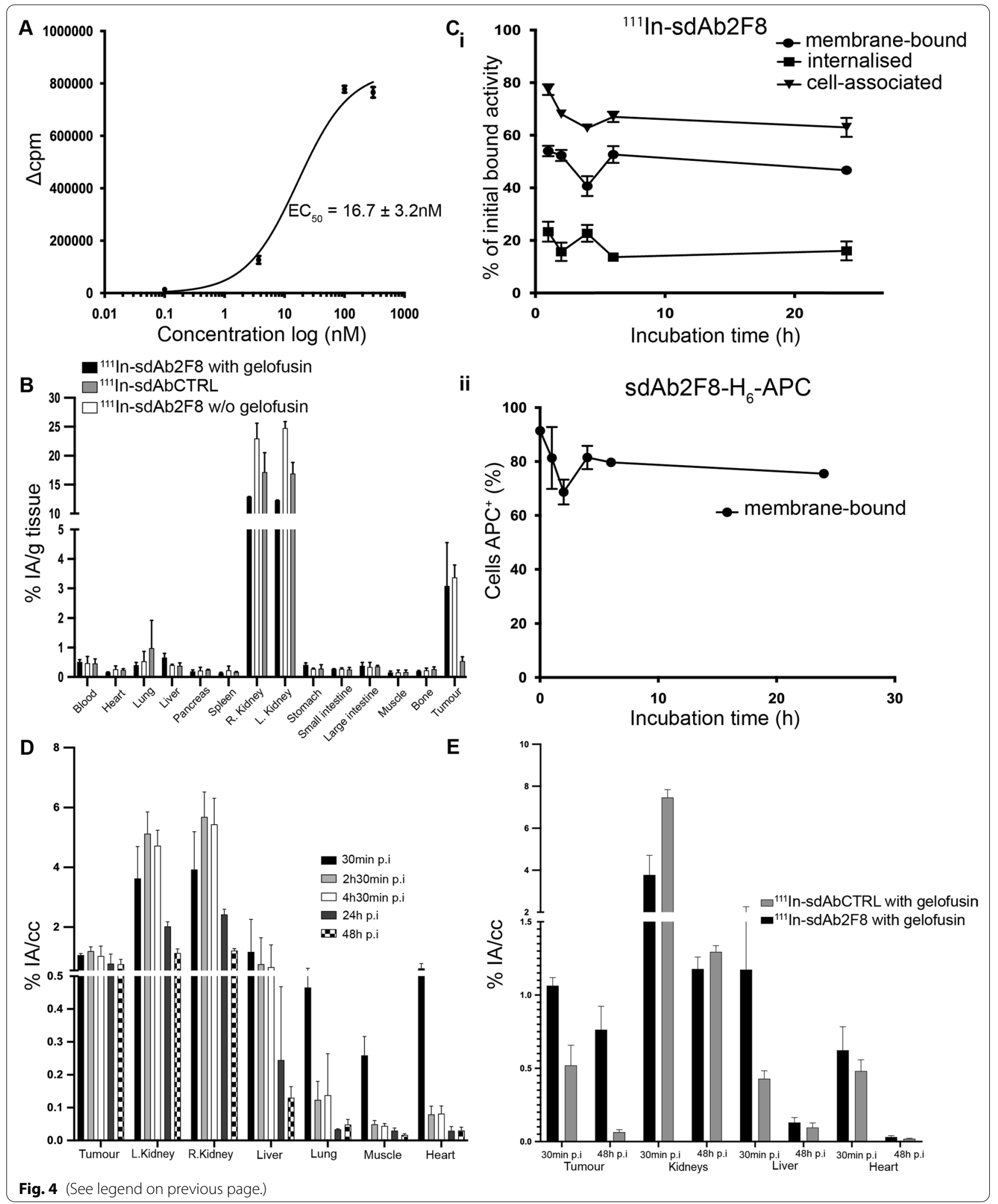



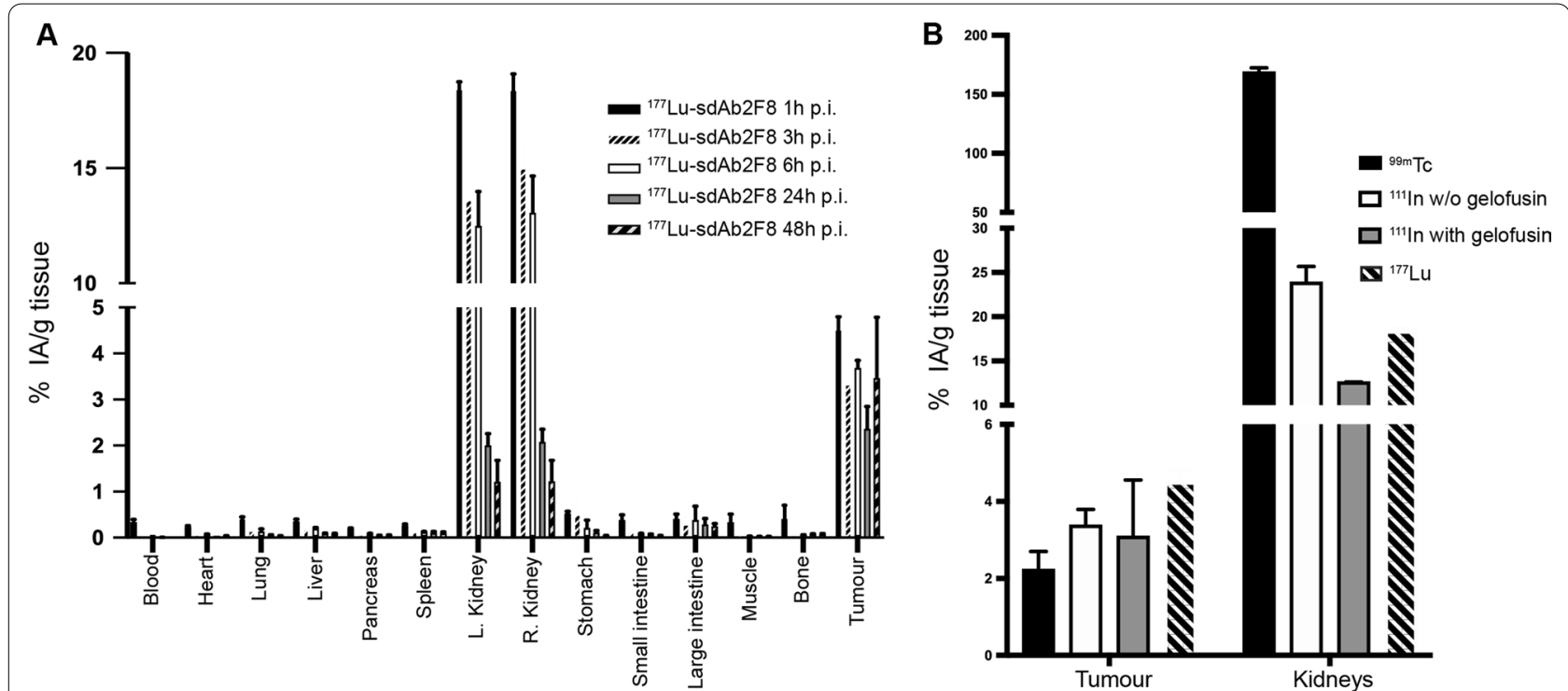

Fig. 5 a Time-dependent biodistribution of ${ }^{177}$ Lu-DTPA-2F8 i.v. co-injected with gelofusin $150 \mathrm{mg} / \mathrm{kg}$ into RPMl 8226 CD38 ${ }^{+}$tumour-bearing mice $\left(10^{5}\right.$ cells injected subcutaneously in the left back side). Values are represented as \% IA/g, obtained after dissection and further detailed in Additional file 1: Table 7. Data are presented as mean $\pm \mathrm{SD}(n=3)$. b Comparison of renal and tumour retention observed for \#2F8 labelled with different radioisotopes $(n=3)$, alone or with $150 \mathrm{mg} / \mathrm{kg}$ gelofusin. Data are expressed as mean \pm SD

with radioactivity and BLI experiments (Figs. 2 and 4). After radiolabelling with ${ }^{111}$ In, both the maximal effective concentration $\left(\mathrm{EC}_{50}\right)$ and the level of internalisation were assessed on RPMI 8226 cells. EC ${ }_{50}$ for ${ }^{111}$ In-DTPA-2F8 measured $16.7 \pm 3.2 \mathrm{nM} .{ }^{111}$ In-DPTA-2F8 bound well to CD38+RPMI 8226 cells but did not induce receptormediated internalisation, as this fraction remained low at all time points until $24 \mathrm{~h}$ (Fig. 4, panel Ci). Flow cytometry confirmed the minor internalisation of sdAb \#2F8 (Fig. 4, panel Cii).

\section{Biodistribution of ${ }^{111} \mathrm{In}$ - and ${ }^{177} \mathrm{Lu}$-labelled sdAb 2F8}

Mice bearing $\mathrm{CD}^{+} 8^{+}$RPMI 8226 tumours were i.v. injected with either ${ }^{111}$ In-DPTA-2F8 alone, ${ }^{111}$ In-DPTA2F8 in combination with $150 \mathrm{mg} / \mathrm{kg}$ gelofusin or ${ }^{111}$ In-DTPA-R3B23. ${ }^{111}$ In-DPTA-2F8 showed high and specific uptake in tumour $1 \mathrm{~h}$ after tracer injection. High levels of radioactivity were observed in kidneys $(23.00 \pm 2.62 \% \mathrm{IA} / \mathrm{g})$ after $1 \mathrm{~h}$, which was reduced by co-injection with $150 \mathrm{mg} / \mathrm{kg}$ gelofusin to only $13.00 \pm 0.02 \%$ IA/g Fig. 4B and Additional file 1: Table 4 . ${ }^{111}$ In-DTPA-R3B23 revealed no relevant uptake in tumour $(0.54 \pm 0.14 \% \mathrm{IA} / \mathrm{g})$, while the amount in kidneys was similar. Uptake of CD38-specific sdAbs in all other organs and tissues was low and considered as background (Fig. 4). A head-to-head comparison of uptake in tumour and kidneys between ${ }^{99 \mathrm{~m}} \mathrm{Tc}-\mathrm{H}_{6}$-tagged-2F8, ${ }^{111} \mathrm{In}$ - and ${ }^{177} \mathrm{Lu}$-labelled untagged-2F8 is depicted in Fig. 5B.
Removal of the hexahistidine tag and co-infusion with $150 \mathrm{mg} / \mathrm{kg}$ gelofusin reduced kidney retention by 86 and $57 \%$, respectively. Uptake in tumour of ${ }^{177} \mathrm{Lu}-\mathrm{DTPA}-2 \mathrm{~F} 8$ co-injected with $150 \mathrm{mg} / \mathrm{kg}$ gelofusin measured about $4.5 \% \mathrm{IA} / \mathrm{g}$ and remained constant over time up to $48 \mathrm{~h}$ p.i. (Fig. 5A). The renal uptake peaked at 18\% IA/g $1 \mathrm{~h}$ after administration and decreased to $2 \% \mathrm{IA} / \mathrm{g}$ at $24 \mathrm{~h}$ p.i. and about $1.2 \% \mathrm{IA} / \mathrm{g}$ at $48 \mathrm{~h}$ p.i. The uptake values over time for different organs and tissues were used for dosimetry calculations. Both tumour and kidneys received the highest absorbed doses per unit of activity, with values of 0.1 and 0.22 Gy per MBq of ${ }^{177} \mathrm{Lu}$-DTPA-2F8 (Additional file 1: Table 7). Absorbed doses to additional organs and tissues measured below 0.006 Gy per MBq.

\section{Therapeutic efficacy of ${ }^{177}$ Lu-DTPA-2F8}

Therapeutic efficacy of ${ }^{177}$ Lu-DTPA-2F8 was assessed in mice bearing $\mathrm{CD}^{2} 8^{+} \mathrm{RPMI} 8226$ tumours. Mice received three i.v. injections of either high radioactive dose $(18.5 \pm 0.5 \mathrm{MBq})$ or low radioactive dose $(9.3 \pm 0.3 \mathrm{MBq})$ regimen of ${ }^{177} \mathrm{Lu}$-DTPA-2F8, or an equal volume of vehicle solution, which led to cumulative absorbed doses to kidneys and tumour of 6.21 and 2.77 Gy, and 12.31 and 5.50 Gy for the low- and high-dose groups, respectively. Figure $6 \mathrm{~A}$ illustrates tumour volume evolution for all three treatment groups. The direct comparison of tumour volumes at day 43 after tumour inoculation revealed a dose-dependent tumour reduction for both 


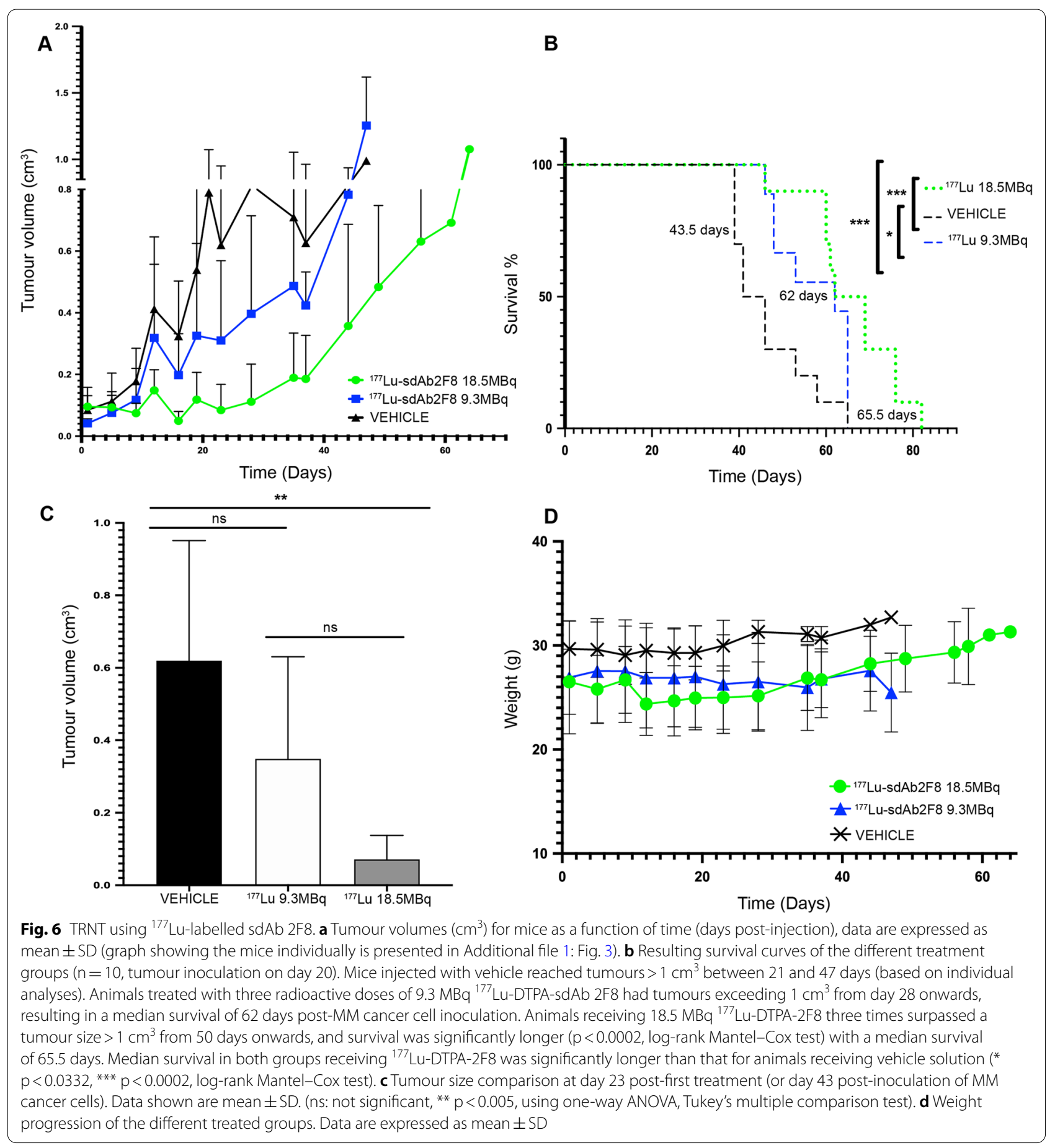

dose regimens compared to vehicle solution (Fig. 6C). These changes were confirmed by similar reduction in tumour burden, quantified by bioluminescence (not shown). The median survival (Fig. 6B) of vehicle-treated mice was 43 days, compared to 62 days for the low radioactive dose regimen $(p=0.027)$ and 65 days for the high radioactive dose regimen $(p=0.0007)$.

\section{Discussion}

The results presented herein highlight the theranostic potential of radiolabelled CD38-targeting sdAb \#2F8 for $\mathrm{MM}$. The radiolabelling of antibodies or Ab-fragments and their subsequent use for nuclear imaging is an attractive tool that helps to assess tumour target expression and distribution in a non-invasive manner. This field of 
nuclear medicine is dramatically expanding by incorporating new conjugation strategies, radiochemistry procedures and $\mathrm{Ab}$ fragments or mimetics. SdAbs, which are the variable binding domains of heavy-chain antibodies, have favourable properties as observed for sdAb \#2F8: they have a low molecular weight of about $12-15 \mathrm{kDa}$ and a straightforward recombinant production in different hosts; moreover, they can be easily conjugated with diagnostic or therapeutic isotopes using standardised radiolabelling procedures without affecting protein affinity for its antigen and thus its targeting potential.Camelidae

$\mathrm{SdAb}$ \#2F8 was chosen based on its favourable biodistribution with a good tumour uptake, the absence of competition with daratumumab and the lack of receptormediated internalisation. Another CD38-binding sdAb, \#1053, was recently conjugated to ${ }^{68} \mathrm{Ga}$ and developed as an imaging probe [25]. Our results indicate that \#1053 competes with daratumumab for binding to CD38 and the seminal work of the group of Koch-Nolte showed that both bind to the same epitope [26].

In contrast to daratumumab, which induces an internalisation of the antigen-antibody complex and a further downregulation of CD38 expression on the MM cell $[27,28]$, sdAb \#2F8 is minimally internalised after CD38 binding. The absence of internalisation is an important feature allowing the realisation of a diagnostic immunePET (positron emission tomography) before a CD38-targeting therapeutic counterpart is given without fearing a reduced antigen expression due to the diagnostic intervention. In addition, as a therapeutic compound, \#2F8 can be administrated repeatedly without affecting CD38 expression. The prolonged localisation of \#2F8 on the cell membrane favours other therapeutic applications such as pretargeting systems that are based on the separation between the administration of the targeting molecule and the radiolabelled agent [29]. The strong binding, long tumour retention and persistence of its extracellular localisation make this sdAb interesting for further integration in such pretargeting system.

Other vectors targeting CD38 have been reported, with a few strategies already evaluated in the clinic [30, 31]. Except for one bispecific construct, all use full-size mAbs as vector. mAbs are known to have a long blood circulation time and slow accumulation in target tissues which requires to wait days after tracer administration before appropriate image contrast is achieved (for daratumumab, the ideal scanning time is between days 5 and 8) [30]. The fast and specific targeting potential of sdAbs in combination with the fast clearance of the unbound fraction in the kidneys (half-time about $20 \mathrm{~min}$ ) allows for a same-day imaging approach, much like the current practice for ${ }^{18} \mathrm{~F}$-FDG-PET [32-34]. While their reduced size favours fast clearance, the biodistribution studies presented herein indicate, however, a high kidney retention as observed with other sdAbs, peptides or scaffold proteins [35]. This high retention can be explained by their glomerular filtration followed by tubular reabsorption and subsequent lysosomal degradation [35]. Strategies for kidney protection that have been proposed include the infusion of positively charged basic amino acids or gelofusin []. In the presented study, the coinjection of radiolabelled 2F8 with gelofusin decreased renal uptake by $57 \% .24,36$

In addition to the diagnostic capacities, \#2F8 was also successfully evaluated in the framework of TRNT. Indeed, repeated administration of \#2F8, coupled to the $\beta^{-}$-particle emitting radionuclide ${ }^{177} \mathrm{Lu}$, resulted in a significant decrease in tumour burden and in a prolonged survival of MM-diseased mice. These responses were dose-dependent with a strong reduction with the high radioactive dose regimen. Repeating low radioactive doses resulted in a similar improvement in survival. This treatment strategy was chosen to mimic a clinical approach of fractionated dosing to lower the toxicity on the surrounding healthy tissues, as used for peptide receptor radionuclide therapy with ${ }^{177} \mathrm{Lu}$-DOTATATE [37].

The group of D. Green and O. Press was the first to develop a CD38-based TRNT approach [38]. Both a classical approach using a directly radiolabelled murine anti-CD38 $\mathrm{mAb}$ and a more innovative pretargeting approach were assessed. In the first pretargeting study, an antibody-SA construct was combined with a radiolabelled biotin [38]. This pretargeting system improved the radioactivity deposition in organs and tissues and delayed tumour development in a therapeutic setting [38]. In a second pretargeting study, the scFv of an antiCD38 mAb and a scFV conjugated to Yttrium-DOTA ligand were merged in a bispecific $\mathrm{Ab}$ fusion protein [7]. This bispecific Ab showed better anti-tumour effects compared to the SA-biotin system when administered to $\mathrm{CD} 38^{+}$tumour-bearing mice. Lastly, an anti-CD38 $\mathrm{mAb}$ was radiolabelled with the alpha-particle emitting radionuclide Astatine-211 ( $\left.{ }^{211} \mathrm{At}\right)$, which also showed to delay tumour growth in MM models with subcutaneous tumours or with minimal residual disease. Other alphaparticle emitters $\left({ }^{212} \mathrm{~Pb},{ }^{225} \mathrm{Ac}\right.$ and $\left.{ }^{213} \mathrm{Bi}\right)$ have been evaluated in the framework of CD38-based TRNT and most indicated strong anti-tumour effects [39-41]. One study directly compared the efficacy of mAbs labelled with the $\alpha$-particle emitting ${ }^{225} \mathrm{Ac}$ or with the $\beta^{-}$-particle emitting ${ }^{177} \mathrm{Lu}$ and found a higher efficacy and less toxicity for the ${ }^{225}$ Ac-labelled variant (42).

Radiolabelled sdAbs are promising theranostic vehicles to follow up disease relapse and to treat disseminated disease. The results presented herein highlight 
the potential of radiolabelled \#2F8 to target CD38 expressing MM lesions. Radiolabelled with diagnostic radioisotopes such as ${ }^{99 \mathrm{~m}} \mathrm{Tc}$ and ${ }^{111} \mathrm{In}, \# 2 \mathrm{~F} 8$ targets CD38 receptor in a fast and specific manner, allowing high-contrast SPECT images early after tracer administration. Repeated administration of ${ }^{177} \mathrm{Lu}$-labelled \#2F8 extends survival of mice significantly compared to controls and in a dose-dependent manner.

\section{Conclusion}

In this study, we identified a new anti-CD38 sdAb fragment that recognises another epitope as the $\mathrm{mAb}$ daratumumab and that is not internalised after binding to CD38. This lead sdAb 2F8 had a favourable biodistribution and was successfully integrated in a therapeutic radio-immunoconjugate that delayed tumour progression and prolonged survival of MM xenografts. Taken together, these results highlight the theranostic potential of our lead sdAb and its relevance towards clinical translation.

\begin{abstract}
Abbreviations
sdAb: Single-domain antibody; TRNT: Targeted radionuclide therapy; MM: Multiple myeloma; mAb: Monoclonal antibody; scFv: Single-chain variable fragments; His and H6: Hexahistidine; SA: Streptavidin; CD: Circular dichroism; s.c.: Subcutaneously; i.v.: Intravenously; RCP: Radiochemical purity; iTLC: Instant thin-layer chromatography; BLI: Biolayer interferometry; SPECT: Single-photon emission computed tomography; CT: Computed tomography; PET: Positron emission tomography; 99mTc: Technetium-99 m; 111 In: Indium-111; 177Lu: Lutetium-177; 211At: Astatine-211; p.i.: Post-injection; \% IA/g: Percentage of the injected activity per gram of tissue mass.
\end{abstract}

\section{Supplementary Information}

The online version contains supplementary material available at https://doi. org/10.1186/s13045-021-01171-6.

Additional file 1. Supplementary information.

\section{Acknowledgements}

We would like to thank the GIGA Cell Imaging and Flow Cytometry platform (ULiège), the Centre for Protein Engineering (ULiège) and the In vivo Cellular and Molecular Imaging lab (Vrije Universiteit Brussel) for their excellent technical assistance. We are grateful for the expert assistance of Sophie Dubois in the different mouse studies.

\section{Authors' contributions}

ED, MD, MDu and JC designed the studies, ED, YL, AK and ML performed experiments and analysed the data. YJZ provided crucial material. ED and JC wrote the manuscript, and $\mathrm{YB}, \mathrm{FB}, \mathrm{MD}, \mathrm{MDu}$ and $\mathrm{ND}$ provided additional input for the manuscript. All authors read and approved the manuscript.

\section{Funding}

The laboratory of Haematology was supported by the Foundation Against Cancer, the Intergroup Francophone du Myélome, the Fonds National de la Recherche Scientifique (FNRS, Belgium), the Fonds Spéciaux de la Recherche (University of Liège) and the CHU de Liège (F.I.R.S.). ED (research fellow), FB (postdoctoral researcher) and M.Du. (Research Associate) have a mandate supported by the FNRS. JC is a post-doctorate clinical specialist funded by the Belgian Foundation against Cancer. M.D. is a postdoctoral fellow of Research Foundation-Flanders (FWO).

\section{Availability of data and materials}

No datasets were generated in this study. Sequences, plasmids or the sdAb 2F8 can be obtained upon request.

\section{Declarations}

\section{Ethics approval and consent to participate}

Mice experiments were approved by the Ethical Committees for Animal Experiments of the University of Liège and of Vrije Universiteit Brussel.

\section{Consent for publication}

Not applicable.

\section{Competing interests}

M.D. and N.D. are, respectively, employee and consultant of Precirix NV and hold ownership interest (including patents) in sdAb radiodiagnostics and radiotherapeutics. N.D. is co-founder of Abscint and together with M.D. cofounder of Precirix NV.

\section{Author details \\ 'Laboratory of Haematology, GIGA-13, University of Liège, Liège, Belgium. ${ }^{2}$ Department of Medical Imaging, Laboratory for In Vivo Cellular and Molecular Imaging, Vrije Universiteit Brussel, Brussels, Belgium. ${ }^{3}$ School of Chemical Biol- ogy and Biotechnology, University Shenzhen Graduate School, Peking, China. ${ }^{4}$ NEPTUNS, Nanobodies To Explore Protein Structure and Functions, Centre for Protein Engineering (CIP), University of Liège, Liège, Belgium. ${ }^{5}$ Division of Haematology, Department of Medicine, University and CHU of Liège, Liège, Belgium.}

Received: 30 June 2021 Accepted: 22 September 2021

Published online: 02 November 2021

\section{References}

1. Kelkar SS, Reineke TM. Theranostics: combining imaging and therapy. Bioconjug Chem. 2011;22(10):1879-903.

2. Kumar SK, Rajkumar V, Kyle RA, Van Duin M, Sonneveld P, Mateos MV, et al. Multiple myeloma. Nat Rev Dis Prim. 2017;3:1-20. https://doi.org/ 10.1038/nrdp.2017.46.

3. van de Donk NWCJ, Richardson PG, Malavasi F. CD38 antibodies in multiple myeloma: back to the future. Blood. 2018;131(1):13-29.

4. Ghai A, Maji D, Cho N, Chanswangphuwana C, Rettig M, Shen D, et al. Preclinical development of CD38-Targeted [(89)Zr]Zr-DFO-Daratumumab for Imaging Multiple Myeloma. J Nucl Med. 2018;59(2):216-22.

5. Li T, Qi S, Unger M, Hou YN, Deng QW, Liu J, et al. Immuno-targeting the multifunctional CD38 using nanobody. Sci Rep. 2016;6:27055.

6. Fumey W, Koenigsdorf J, Kunick V, Menzel S, Schutze K, Unger M, et al. Nanobodies effectively modulate the enzymatic activity of CD38 and allow specific imaging of CD38(+) tumors in mouse models in vivo. Sci Rep. 2017;7(1):14289.

7. Green DJ, O'Steen S, Lin Y, Comstock ML, Kenoyer AL, Hamlin DK, et al. CD38-bispecific antibody pretargeted radioimmunotherapy for multiple myeloma and other B-cell malignancies. Blood. 2018 ;131(6):611-20.

8. D'Huyvetter M, Xavier C, Caveliers V, Lahoutte T, Muyldermans S, Devoogdt N. Radiolabeled nanobodies as theranostic tools in targeted radionuclide therapy of cancer. Expert Opin Drug Deliv. 2014;11(12):1939-54.

9. Pain C, Dumont J, Dumoulin M. Camelid single-domain antibody fragments: Uses and prospects to investigate protein misfolding and aggregation, and to treat diseases associated with these phenomena. Biochimie. 2015;111:82-106.

10. Dumoulin M, Conrath K, Van Meirhaeghe A, Meersman F, Heremans K, Frenken LGJ, et al. Single-domain antibody fragments with high conformational stability. Protein Sci. 2002;11(3):500-15.

11. Muyldermans S. A guide to: generation and design of nanobodies. FEBS J. 2021;288(7):2084-102. 
12. Ackaert C, Smiejkowska N, Xavier C, Sterckx YGJ, Denies S, Stijlemans $B$, et al. Immunogenicity Risk Profile of Nanobodies. Front Immunol. 2021;12(March).

13. Conrath KE, Lauwereys M, Galleni M, Matagne A, Frère JM, Kinne J, et al. $\beta$-Lactamase inhibitors derived from single-domain antibody fragments elicited in the Camelidae. Antimicrob Agents Chemother 2001;45(10):2807-12.

14. An N, Hou YN, Zhang QX, Li T, Zhang QL, Fang C, et al. Anti-multiple myeloma activity of nanobody-based anti-CD38 chimeric antigen receptor T cells. Mol Pharm. 2018;15(10):4577-88.

15. Skerra A, Pluckthun A. Assembly of a functional immunoglobulin Fv fragment in Escherichia coli. Science (80- ). 1988;240(4855):1038 LP - 1041.

16. El Hajjaji H, Dumoulin M, Matagne A, Colau D, Roos G, Messens J, et al. The zinc center influences the redox and thermodynamic properties of Escherichia coli thioredoxin 2. J Mol Biol. 2009;386(1):60-71.

17. Dheur M-S, Poirel HA, Ameye G, Tilman G, Saussoy P, Defour J-P, et al. Characterization of two new high-grade B-cell lymphoma cell lines with MYC and BCL2 rearrangements that are suitable for in vitro drug sensitivity studies. Leuk Lymphoma. 2019;60(4):1043-52.

18. Lejeune M, Duray E, Peipp M, Clemenceau B, Baron F, Beguin Y, et al. Balancing the CD38 expression on effector and target cells in daratumumab-mediated NK Cell ADCC in the multiple myeloma context. Cancers (Basel). 2021;13.

19. Xavier C, Devoogdt N, Hernot S, Vaneycken I, D'Huyvetter M, De Vos J, et al. Site-specific labeling of his-tagged Nanobodies with (9)(9)mTc: a practical guide. Methods Mol Biol. 2012;911:485-90.

20. Vaneycken I, Devoogdt N, Van Gassen N, Vincke C, Xavier C, Wernery U, et al. Preclinical screening of anti-HER2 nanobodies for molecular imaging of breast cancer. FASEB J. 2011;25(7):2433-46.

21. Loening AM, Gambhir SS. AMIDE: a free software tool for multimodality medical image analysis. Mol Imaging. 2003;2(3):131-7.

22. D'Huyvetter M, Vincke C, Xavier C, Aerts A, Impens N, Baatout S, et al. Targeted radionuclide therapy with A 177Lu-labeled anti-HER2 nanobody. Theranostics. 2014;4(7):708-20.

23. Krasniqi A, D'Huyvetter M, Xavier C, Van der Jeught $K$, Muyldermans $S$, Van Der Heyden J, et al. Theranostic radiolabeled Anti-CD20 sdAb for targeted radionuclide therapy of non-hodgkin lymphoma. Mol Cancer Ther. 2017:16(12):2828-39.

24. Rolleman EJ, Valkema R, de Jong M, Kooij PPM, Krenning EP. Safe and effective inhibition of renal uptake of radiolabelled octreotide by a combination of lysine and arginine. Eur J Nucl Med Mol Imaging. 2003;30(1):9-15.

25. Wang C, Chen Y, Hou YN, Liu Q, Zhang D, Zhao H, et al. ImmunoPET imaging of multiple myeloma with [(68)Ga]Ga-NOTA-Nb1053. Eur J Nucl Med Mol Imaging. 2021 Feb;

26. Fumey W, Koenigsdorf J, Kunick V, Menzel S, Schütze K, Unger M, et al. Nanobodies effectively modulate the enzymatic activity of CD38 and allow specific imaging of CD38+tumors in mouse models in vivo. Sci Rep. 2017;7(1):1-13.

27. Ghose J, Viola D, Terrazas C, Caserta E, Troadec E, Khalife J, et al. Daratumumab induces CD38 internalization and impairs myeloma cell adhesion. Oncoimmunology. 2018;7(10):e1486948.

28. Nijhof IS, CasneufT, van Velzen J, van Kessel B, Axel AE, Syed K, et al. CD38 expression and complement inhibitors affect response and resistance to daratumumab therapy in myeloma. Blood. 2016;128(7):959-70.
29. Goodwin D, Meares C, Diamanti C, McCall M, Lai C, Torti F, et al. Use of specific antibody for rapid clearance of circulating blood background from radiolabeled tumor imaging proteins. Eur J Nucl Med. 1984;9(5):209-15.

30. Ulaner GA, Sobol NB, O'Donoghue JA, Kirov AS, Riedl CC, Min R, et al. CD38-targeted Immuno-PET of Multiple Myeloma: From Xenograft Models to First-in-Human Imaging. Radiology. 2020;295(3):606-15.

31. Krishnan A, Adhikarla V, Poku EK, Palmer J, Chaudhry A, Biglang-Awa VE, et al. Identifying CD38+ cells in patients with multiple myeloma: firstin-human imaging using copper-64-labeled daratumumab. Blood Adv. 2020;4(20):5194-202.

32. Krasniqi A, D'Huyvetter M, Devoogdt N, Frejd FY, Sorensen J, Orlova A, et al. Same-Day Imaging Using Small Proteins: Clinical Experience and Translational Prospects in Oncology. J Nucl Med. 2018;59(6):885-91.

33. Keyaerts $M$, Xavier C, Heemskerk J, Devoogdt N, Everaert H, Ackaert C, et al. Phase i study of 68Ga-HER2-Nanobody for PET/CT assessment of HER2 expression in breast carcinoma. J Nucl Med. 2016;57(1):27-33.

34. D'Huyvetter M, De Vos J, Caveliers V, Vaneycken I, Heemskerk J, Duhoux FP, et al. Phase I trial of (131)I-GMIB-Anti-HER2-VHH1, a new promising candidate for HER2-targeted radionuclide therapy in breast cancer patients. J Nucl Med. 2020 Dec;

35. Behr TM, Goldenberg DM, Becker W. Reducing the renal uptake of radiolabeled antibody fragments and peptides for diagnosis and therapy: present status, future prospects and limitations. Eur J Nucl Med. 1998;25(2):201-12.

36. Vegt E, Wetzels JFM, Russel FGM, Masereeuw R, Boerman OC, van Eerd $J E$, et al. Renal uptake of radiolabeled octreotide in human subjects is efficiently inhibited by succinylated gelatin. J Nucl Med. 2006;47(3):432-6

37. Kwekkeboom DJ, de Herder WW, Kam BL, van Eijck CH, van Essen M, Kooij PP, et al. Treatment with the radiolabeled somatostatin analog [177 Lu-DOTA 0, Tyr3] octreotate: toxicity, efficacy, and survival. J Clin Oncol Off J Am Soc Clin Oncol. 2008;26(13):2124-30.

38. Green DJ, Orgun NN, Jones JC, Hylarides MD, Pagel JM, Hamlin DK, et al. A preclinical model of CD38-pretargeted radioimmunotherapy for plasma cell malignancies. Cancer Res. 2014;74(4):1179-89.

39. Quelven I, Monteil J, Sage M, Saidi A, Mounier J, Bayout A, et al. (212)Pb a-Radioimmunotherapy Targeting CD38 in Multiple Myeloma: A Preclinical Study. J Nucl Med. 2020;61(7):1058-65.

40. Cherel M, Gouard S, Gaschet J, Sai-Maurel C, Bruchertseifer F, Morgenstern A, et al. 213Bi radioimmunotherapy with an anti-mCD138 monoclonal antibody in a murine model of multiple myeloma. J Nucl Med. 2013;54(9):1597-604

41. Dawicki W, Allen KJH, Jiao R, Malo ME, Helal M, Berger MS, et al. Daratumumab-(225)Actinium conjugate demonstrates greatly enhanced antitumor activity against experimental multiple myeloma tumors. Oncoimmunology. 2019;8(8):1607673.

42. Minnix M, Adhikarla V, Caserta E, Poku E, Rockne R, Shively JE, et al. Comparison of CD38 targeted alpha- vs betaradionuclide therapy of disseminated multiple myeloma in an animal model. J Nucl Med. 2021;62(6):795-801.

\section{Publisher's Note}

Springer Nature remains neutral with regard to jurisdictional claims in published maps and institutional affiliations.

Ready to submit your research? Choose BMC and benefit from:

- fast, convenient online submission

- thorough peer review by experienced researchers in your field

- rapid publication on acceptance

- support for research data, including large and complex data types

- gold Open Access which fosters wider collaboration and increased citations

- maximum visibility for your research: over 100M website views per year

At BMC, research is always in progress.

Learn more biomedcentral.com/submissions 